\title{
Evaluation of Distribution Environment in LTL Shipment between Central Europe \& South Africa
}

\author{
Péter Böröcz \\ Széchenyi István University \\ boroczp@sze.hu \\ Paul Singh \\ Michigan State University \\ packlawusa@gmail.com
}

Jay Singh

California Polytechnic State University - San Luis Obispo

jasingh@,calpoly.edu

\begin{abstract}
Due to the global expansion of transportation and handling companies, the distribution and supply chains of both raw materials and finished products now requires a better understanding of the shipping environment. This international shipping and handling information describing the physical and climatic conditions provides packaging engineers the required technical information to design better packaging to provide protection to products in various segments of the supply chain. In these global supply chains, products emerging from Central Europe also play an increasingly important role today. From this region, the truck and vessel combination is the most dominant transportation mode for non-time sensitive shipments between continents, mainly for shipments not exceeding the volume of a full container or truckload. Most previous studies mainly focused on regional or domestic measurement, using a single shipment mode that was dependent on the dynamics of a single transport vehicle. This study however focuses on measuring the transportation environment effects (vibration levels, shocks, changes of temperature and relative humidity) in a less-than-truckload shipment using multiple modes of transport in trucks and vessels between two companies and continents, originating from Hungary and ending in South Africa over several weeks. This study aims to provide results for this distribution environment while traveling from the northern hemisphere in Eastern Europe to the southern hemisphere in South Africa.
\end{abstract}

Key Words: vibration, temperature, relative humidity, truck, ship, packaging, LTL 


\section{INTRODUCTION}

From the early 1990s the economies of Central and Eastern Europe have started to compete with other capital markets in the free economies of today's global trade. The multinational companies from this region mainly export their value-added products to other regions in the world [1]. The performance of these European economies in the aggregate GDP concerning exports of goods was $3.5 \%$ compared to the total global GDP in 2011 [2]. These semi-finished product-manufacturing companies have particular emphasis in the electronics industry. Most of the goods transported from this region use multiple modes of transport (ship, rail and truck).

In order to accomplish this significant increase in global trade, there has been an increase in maritime shipping to accommodate both full container and less than truck-load shipments. It is therefore important to measure, analyze and develop test methods that represent the multi-mode transportation which involves both ground and sea transport. The volume of global seaborne trade in 2012 was $9,183.7$ million tons, which is $16.5 \%$ higher than the volume in 2006 [3]. It must be noted that most of the shipments representing the above volume are usually "less than truckload" or "less than container-load" (LTL) units. These partial and nonhomogenous truck or container loads also increase the number of handlings and operations, constantly switching to truck, to rail, to vessel, with or without mechanical or manual handlings. In today's world of maritime shipping freight forwarders the transportation companies prefer ISO containers, as they are easy to handle and transfer between various modes of transport (truck, rail and ship). The global container port throughput increased by an estimated $3.8 \%$ to 601.8 million 20 -foot equivalent units in 2012. In 2013, loaded containers amounted to 1,578 million tons compared to the 598 million in 2000 .
It is important to note here that the vessel capacity and size have almost doubled since 2004, from 2,812 twenty-foot equivalent unit (TEU) ten years ago to 5,540 TEU in 2013 [3].

The shipment of commodities and non-time sensitive products generally take longer time to ship between source and destination, and often involve more handlings at ports and terminals to allow passage of time-critical shipments. The transport and handling of these types of these shipments produce both physical and climatic events that can affect the integrity of the products being protected by the packaging materials and systems. The most common physical events include vibration, impacts and compression, whereas the most common climatic inputs of concern are temperature and relative humidity $(\mathrm{RH})$ exposure [4].

Due to the above mentioned conditions, physical distribution environments are becoming more complex, and the dynamic inputs during distribution can affect packaged products. In order to ensure the efficiency of the protective distribution packaging in these complex systems and to deliver a safe product, a comprehensive knowledge of physical and climatic events during transportation and handling in the entire supply chain is required.

Since the physical and environmental hazards during distribution are random, it is important to incorporate some level of safety measure in the protective packaging system design. Most packaging systems that are developed to provide protection to products against physical hazards typically incorporate a certain degree of safety factor. Therefore, if the exact level of hazard is not known, it is preferable to have a certain degree of overpackaging than under-packaging. Under-packaging or a less-than-optimum protection can cause damage to the product within, which has a negative impact 
on the environment than slight over-packaging. Replacing a damaged product requires a new product, new package and a re-use of all resources to deliver the replacement. In addition to the environmental burdens it also produces significant customer dissatisfaction and lost sales. Hence, it is important to be slightly over-packaged when the optimum levels of protection are not known to create an "optimum-package". Therefore, the packaging designers and engineers rely on historical data and methods that ensure a final, safe and damage-free shipment at low costs.

Previous studies have measured and analyzed vibration levels and developed power spectral density (PSD) profiles for different modes of transportation in various countries including the US [5], India [6], Brazil [7] and Spain [8], Thailand [9]. Factors involving changes in vibration levels including payloads, suspensions (leaf spring vs. air ride) and road condition have been previously investigated [10, 11]. Vibration levels in less-thantruckload (LTL) shipments trailers have also been studied [12]. Data has also been previously collected on comparing vibration levels in small and medium package delivery vehicles including small-sized and medium-sized truck, pick-up truck, van and automobiles [13]. Recently, the vibration levels in two-wheel and three-wheel motorcycles have also been measured [14]. These vehicles are commonly used for "last leg" distribution in Asia. In addition to the physical data, the vibration and temperature in the global intermodal container shipments on truck, rail and ship from India to the US, and Brazil to US have been studied in intermodal container shipments [15]. The results show that highest vibration levels occur on truck travel on poor road conditions followed by rail and ship travel. A study also investigated the dynamic and climatic environment in refrigerated ocean vessels from Central America to the destinations in Europe and the US [16].
In summary, the results from these previous studies show that vibration levels are different among different modes of transportation, and are generally higher in truck and rail transport than ship transport. In addition, the temperature extremes are often more predominant in inland components of distribution and not at ports or at sea. Relative humidity varies depending on conditions from dry weather to rain. The impact and damage associated with vibration levels from transportation environment on the product and packaging has also been previously studied [17]. Researchers have also presented packaging and loading methods to reduce damage for various less than truck load shipments for products such as paint drums, flat screen televisions and copiers [18-21].

In reviewing the literature on this subject as discussed above, the authors are not aware of studies documenting transportation environment as part of LTL shipments involving multi-modes of transport (truck and ship) from Eastern and Central Europe to Africa and going across the Equator. Therefore this paper will provide insight into the physical and climatic environments that exist in this region and the impact of physical and climatic effects on LTL shipments in multi-mode transport among continental Europe and Africa.

The focus of this study was to measure and analyze the physical and climatic conditions during transportation and handling (vibration, shocks, temperature and relative humidity) in a LTL unit shipped via multiple transport modes (truck and ship) between two companies and two continents, from Hungary to South Africa. The shipment consisted of electrical automotive parts, which are manufactured in Miskolc, Hungary and exported to Uitenhage, Republic of South Africa (RSA). The shipper has a long-term existing relationship with its subsidiary in RSA. The entire route is shown in 
Figures $1 \mathrm{a}, 1 \mathrm{~b}$ and 2 . This study does not examine the effect of vehicles used, their velocity, the road conditions and the different payloads but reports on the measured levels of physical and climatic hazards through the whole trip as a collective international multi-modal shipment.
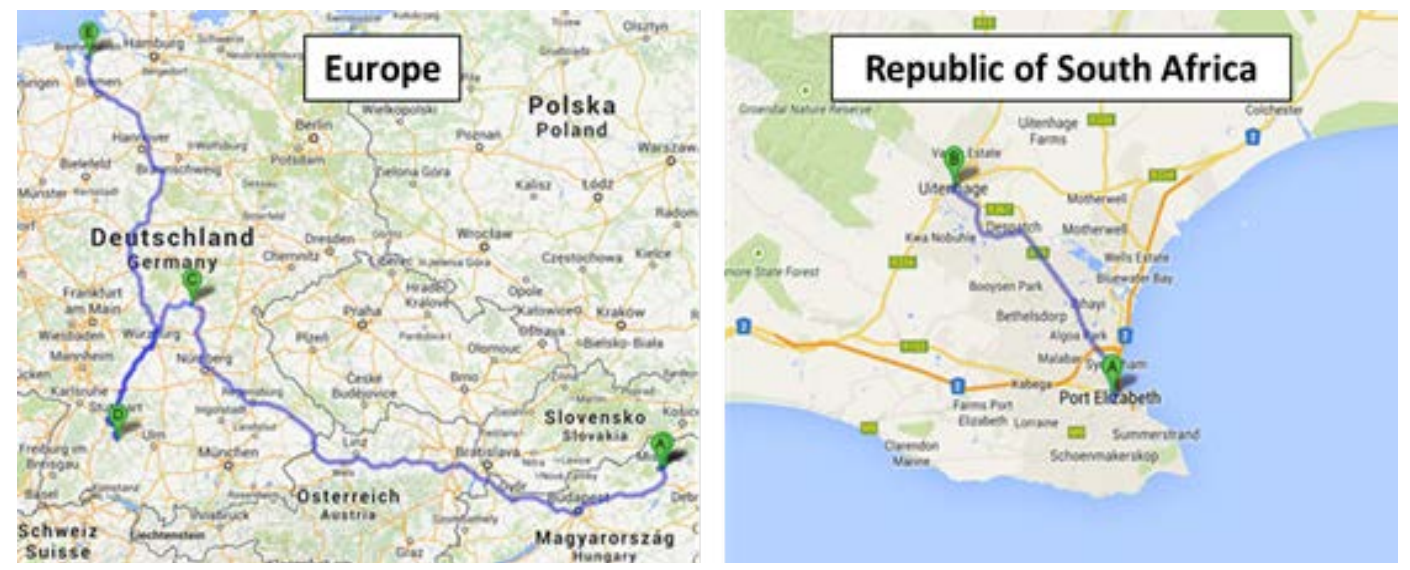

Figures 1a and 1b: The Measured Continental Transportation Routes (in Europe and in the Republic of South Africa)

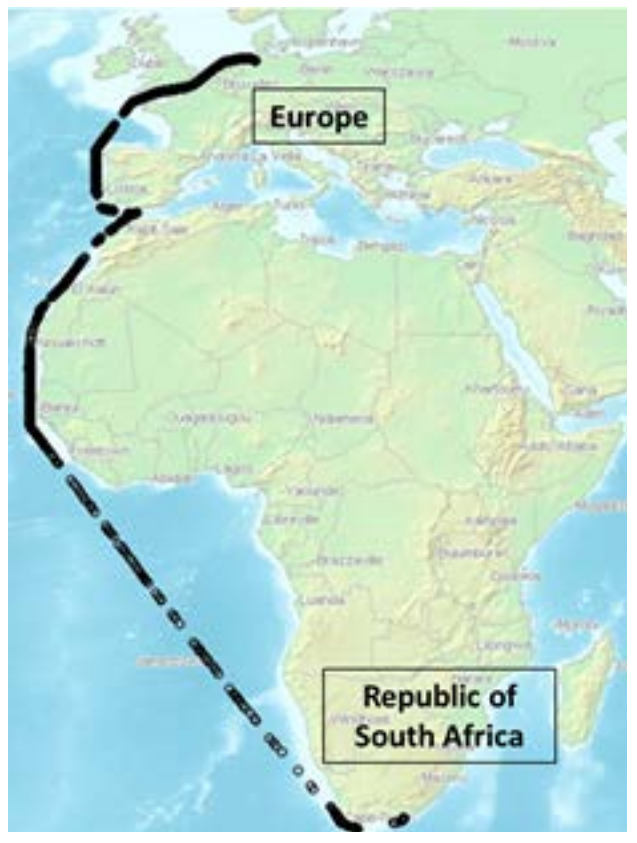

Figure 2: The Measured Maritime Route (based on the GPS signal of the vessel) 


\section{TRANSPORTATION ROUTE AND PACKAGING SYSTEM}

\section{Transportation Route}

The entire shipment was measured for shock, vibration, temperature and RH changes. In this study the "less than truck" unitized load first traveled from the manufacturing site to the storage facility near Miskolc, Hungary, and then to the central storage facility of the manufacturer in Germany (Figures 1a and 1b). From here it again traveled by truck to the port in Bremerhaven (Germany). It then traveled by ship to South African port of Port Elizabeth with a stop in Algeciras (Spain). It was then unloaded from the ship and traveled further by truck inland in South Africa to the final customer destination. The shipment traveled a distance of approximately $2,128 \mathrm{~km}$ on a route that included highways, innercity roads, and two-lane roads. The recorded data accounted for two commissioning occasions and at least ten handlings representing loading and unloading of the load between various transportation segments. The measurement for this study was conducted between April 17, 2014 and July 7, 2014 for a total of 82 days. The details of the route and specific locations where the load arrived by date are shown in Table 1.

\section{Packaging System}

The test shipment monitored in this study consisted of a unitized load shown in Figure 3. The unit was designed to protect the product effectively from mechanical shock and extreme climatic conditions. All packaging system components were designed for one-way distribution. The load consisted of twenty shippers, each carrying six individually packaged products within. Each shipper was made from a tripe wall corrugated tray style box $(530 \mathrm{~g} / \mathrm{m} 2,6.7 \mathrm{kN} / \mathrm{m}$ and $800 \mathrm{kPa})$ with a telescopic removable lid. An expanded polystyrene (EPS) foam tray was used to encapsulate and cushion the products. Furthermore a disposable $1000 \mathrm{~mm} \mathrm{x}$ $1200 \mathrm{~mm}$ wooden pallet, paperboard edge protectors and plastic straps were also used to create the unit load. Each individual package was $380 \mathrm{~mm}$ x 560 $\mathrm{mm} \times 250 \mathrm{~mm}$ (external dimensions) in size and weighed approximately $7.5 \mathrm{~kg}$. The whole unit load weighed approximately $170 \mathrm{~kg}$ with approximate dimensions of $1200 \mathrm{~mm} \times 1000 \mathrm{~mm} \times 1140 \mathrm{~mm}$. The cart and casters in Figure 3 are not part of the package system but were used to move the unit load in the storage area.

\begin{tabular}{l|rrr}
\hline Stage & Date & Location & Activity \\
\hline- & $17 \mathrm{Apr}-18 \mathrm{Apr}$ & Miskolc (HUN) & Indoor storage \\
$\mathbf{1}$ & $18 \mathrm{Apr}$ & En route & Forwarding by truck $(9 \mathrm{~km})$ \\
- & $18 \mathrm{Apr}-25 \mathrm{Apr}$ & Felsözsolca (HUN) & Indoor storage \\
$\mathbf{2}$ & $25 \mathrm{Apr}$ & En route & Forwarding by truck (1.053 km) \\
- & $25 \mathrm{Apr}-27 \mathrm{Apr}$ & Bad Rodach (GER) & Commissioning \\
$\mathbf{3}$ & $27 \mathrm{Apr}-28 \mathrm{Apr}$ & En route & Forwarding by truck (305 km) \\
- & $28 \mathrm{Apr}-7 \mathrm{May}$ & Reutlingen (GER) & Loaded into container, outdoor storage \\
$\mathbf{4}$ & $7 \mathrm{May}$ & En route & Forwarding by truck (727 km) \\
- & $8 \mathrm{May}-12 \mathrm{May}$ & Bremerhaven (GER) & Outdoor storage in container \\
$\mathbf{5}$ & $12 \mathrm{May}-5 \mathrm{Jun}$ & En route & Forwarding by vessel \\
- & $6 \mathrm{Jun}-25 \mathrm{Jun}$ & Port Elizabeth (RSA) & Outdoor storage in container \\
$\mathbf{6}$ & $25 \mathrm{Jun}$ & En route & Forwarding by truck (34 km) \\
- & $26 \mathrm{Jun}-7 \mathrm{Jul}$ & Uitenhage (RSA) & Indoor storage \\
\hline
\end{tabular}

Table 1: Details of Various Stages of Entire Shipment 


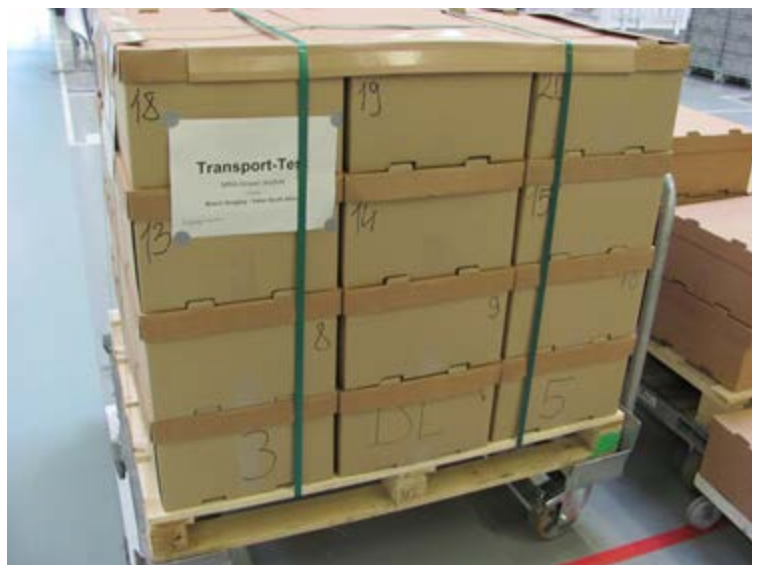

Figure 3: Instrumented Unitized Load

\section{INSTRUMENTATION AND RECORDING PARAMETERS}

\section{Measurement Equipment and Set-Up}

In this study a Lansmont (SAVER) ${ }^{\mathrm{TM}} 3 \mathrm{X} 90$ field data recorder (Lansmont Corp., Monterey, CA, USA) was used to collect the data. In addition Saver Xware and Microsoft Excel (Rank \& Percentile and database count functions) software packages were also used for analyzing data. The recorder has a piezoelectric tri-axial accelerometer as well as a temperature and humidity sensor with a built-in microprocessor. The recorder has a lithium-ion battery, which is able to provide power for recording data for approximately 90 days. The recorder measured shock impacts in all three orientations, vibration levels (vertical, lateral and longitudinal direction), and temperature and relative humidity conditions inside the package that occurred during the whole shipment. The internal clock of the equipment was calibrated to Central European Time standard
The settings of the recorder used in this study are shown below:

\section{SIGNAL Triggered Data:}

- Signal pre-trigger: $20 \%$

- Signal post-trigger: $50 \%$

- Signal-trigger threshold level: $3.0 \mathrm{G}$

- Acceleration range: $1-100 \mathrm{G}$

- Filter frequency: $250 \mathrm{~Hz}$

\section{TIMER Triggered Data:}

- Recording Time: $1.024 \mathrm{msec}$

- Sample/sec: 1000

- Sample size: 1024

- Wakeup Interval: every 10 minutes

- Filter frequency: $250 \mathrm{~Hz}$ 
The vibration levels were recorded both using the timer interval and all events that exceeded the trigger threshold level of $3.0 \mathrm{G}$. The recorder was turned on before the final unitizing of package system and turned off when the product had been unpacked or arrival at customer destination.

The recorder was mounted directly to the wooden pallet, located to the center of the outside upper slat, with screws. Figures $4 \mathrm{a}$ and $4 \mathrm{~b}$ represent the location and the mounting of the equipment. Thus it was ensured that the sensors of the equipment could be inside of the packaging and record the direct input excitation of the transport system.
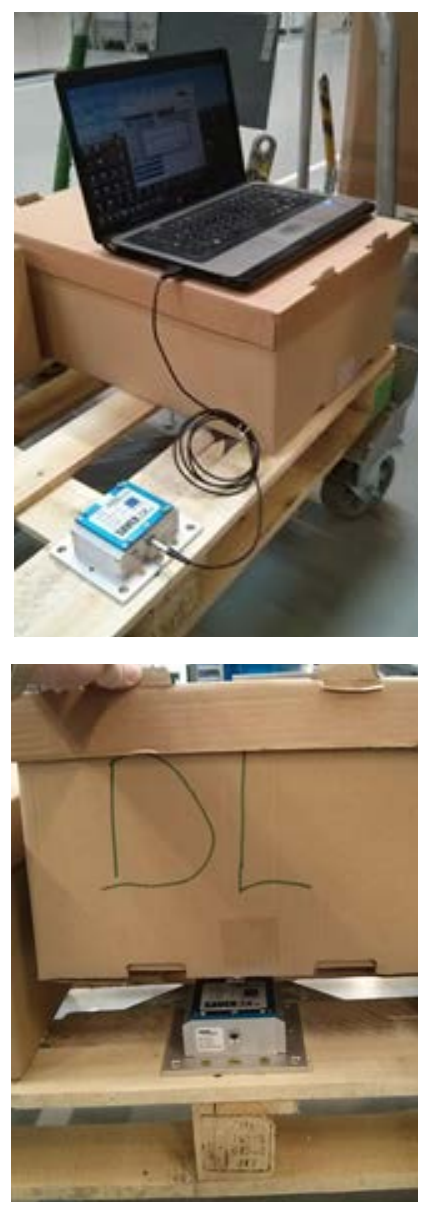

Figure 4a and 4b: Mounting Location of the Recorder
Over the three month total distribution period consisting of 82 days of actual transit and storage, the package system was exposed to varying ambient and physical conditions. The transit included several different modes of transportation (trucks and ships) and surface conditions. As mentioned earlier it is virtually impossible for the shipper and manufacturer to sleect the types of trucks, exact travel routes and locations on the ship for this type of LTL shipment. According to the freight forwarders' certificate a regular MAN semi-trailer (MAN Truck International, Stockholm, Sweden) was used to move the load from Felsőzsolca to Bad Rodach with a total payload of $19800 \mathrm{~kg}$. Subsequently, semitrailers were also used to move the ISO container in which the unit load was loaded prior to going out to sea, and were also used for moving to and from the commissioning center. According to MAERSK, whose container was used in this study, the container was located on the front deck leve

\section{Data Analysis}

In the case of vibration analysis power density (PD) levels were determined as a function of frequency, based on the recorded random vibration acceleration levels. The average PD within a narrow band of frequencies of a given spectrum can be determined by root mean square acceleration (Grms) values based on the number of samples for a given bandwidth [11]. The metric of Grms is typically used to specify and compare the energy in repetitive shock vibration systems. The vibration environment can be represented by a power density spectrum (PDS), a plot of the average power density level versus frequency. This method of representing vibration levels by PDS provides a method to compare various transportation environments, and it can be used to simulate these levels using programmable vibration tables [5]. 
In this study vibration data was filtered to remove all outlier events such as any noise or nonvibration related movements from the analysis. This way any data below $0.01 \mathrm{Grms}$ was filtered out. The power density spectrums were then created using the remaining measured data and represent a commonly used method in which a spectrum for the top 5 and 20 percent of the highest measured data are shown and then followed by a lower spectrum representing the remainder 80 percent of all recorded data. The PSD plots in this paper are presented for stage 2 of the distribution (Table 1). The reason for leaving the other three stages is short segments with limited data and lack of information about the vehicle and real payload. Therefore spectrums are presented for the top 5 and 20 percent of saved events and bottom 80 percent of remaining events [9][13][15]. In addition a spectrum representing the average for all events measured is also presented. Power density spectrums in all three axes (lateral, longitudinal and vertical) are presented in this paper. Each PDS is reported with a Kurtosis $(\mathrm{K})$ value based on recorded acceleration time histories in order to provide probability distributions with more information.

In addition to the spectrums, the measured levels of temperature and relative humidity changes are also shown as a function of time. This data was recorded based on the time trigger used by the recorder based on an interval of 10 minutes for the entire shipment

\section{DATA AND RESULTS}

The data representing the climatic environment was first analyzed showing the measured temperature and relative humidity levels during the entire 82 days of shipment consisting of both land and sea. Due to the movements across the equator, it must be noted that the early summer or spring season in Europe during April and May at the start of the shipment changes to an autumn or winter in South Africa during June and July. All recorded data contain measurement values for all climate zones from northern hemisphere to equator and then to the southern hemisphere. Hence, according to the Köppen classification [23], the shipment traveled through oceanic, dry and humid, and Mediterranean climate zones. Figure 5 presents the temperature values recorded inside the shipper during this trip. The maximum and minimum temperature and $\mathrm{RH}$ values were measured to be $27.23{ }^{\circ} \mathrm{C}$ and $9.19{ }^{\circ} \mathrm{C}$, with RH values varying between $29.98 \%$ to $79.07 \%$ $\mathrm{RH}$. The figure shows an almost linear increase and decrease of the temperature and constant level of $\mathrm{RH}$ when the ship was near the Equator. Also Figure 6 shows the daily diurnal effect of temperature rise and fall when the unit load was at Port Elizabeth. 


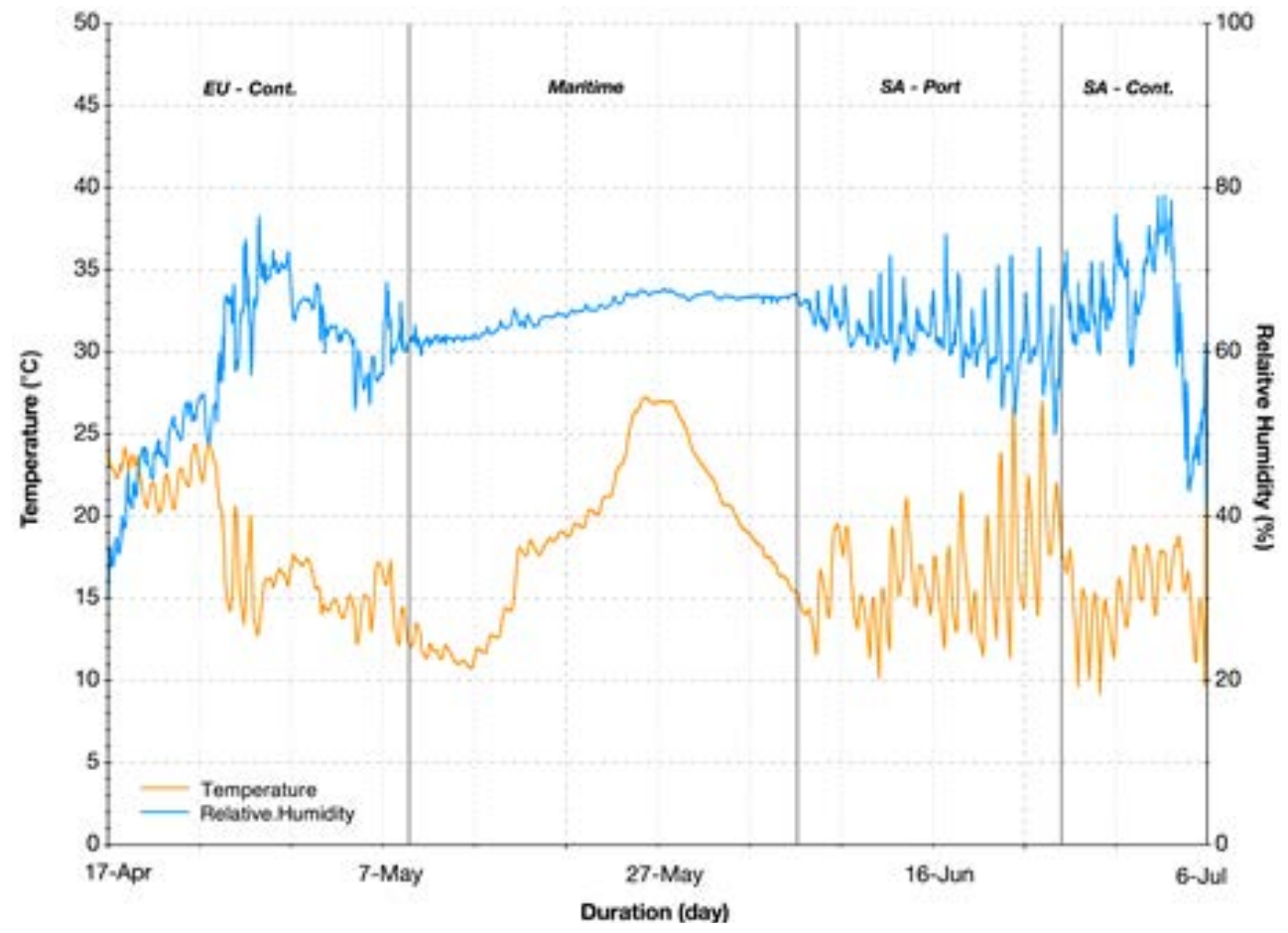

Figure 5: Timer Triggered Temperature and Relative Humidity (RH) Values

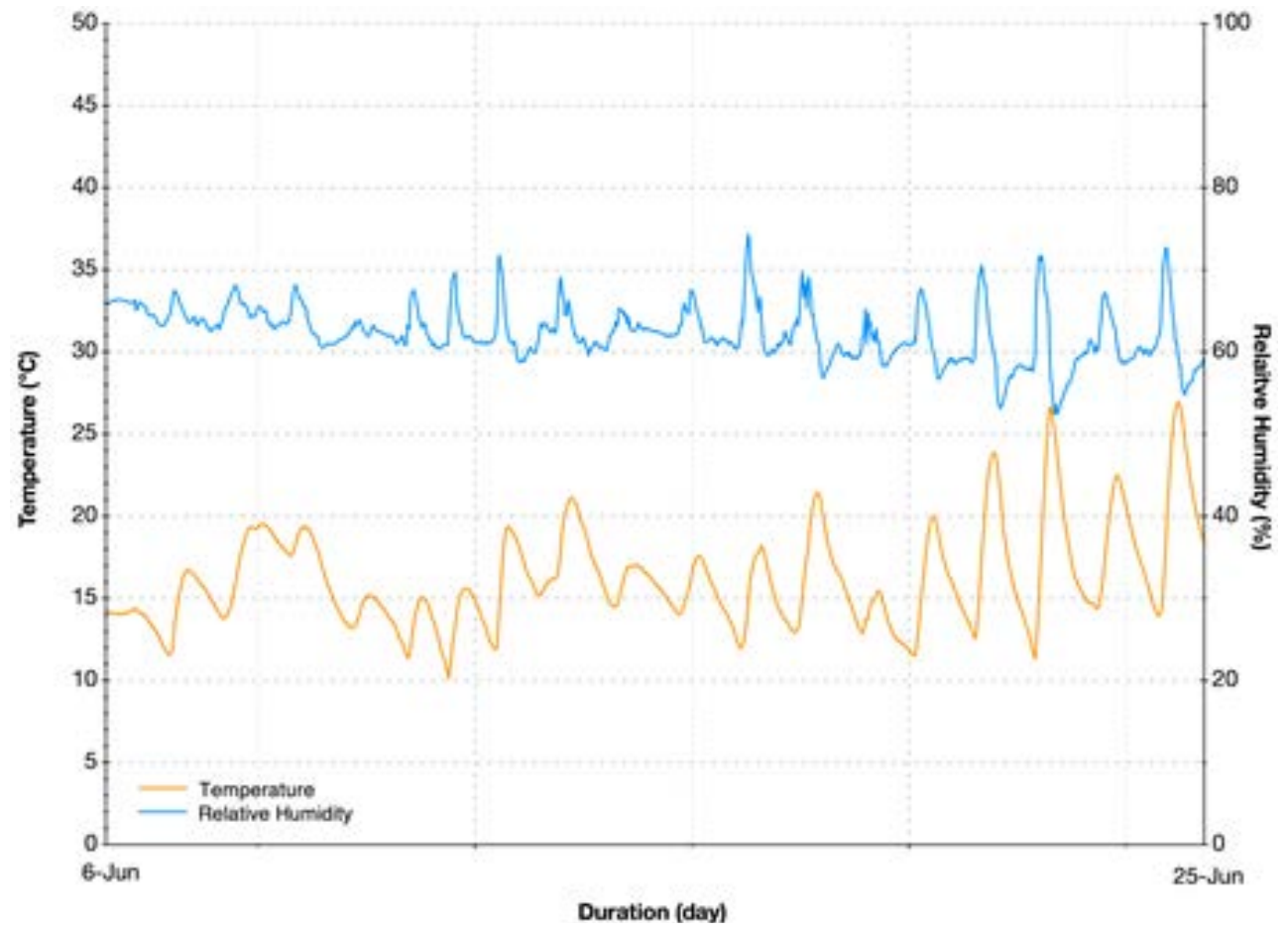

Figure 6: Temperature and RH Values at Port Elizabeth, South Africa 


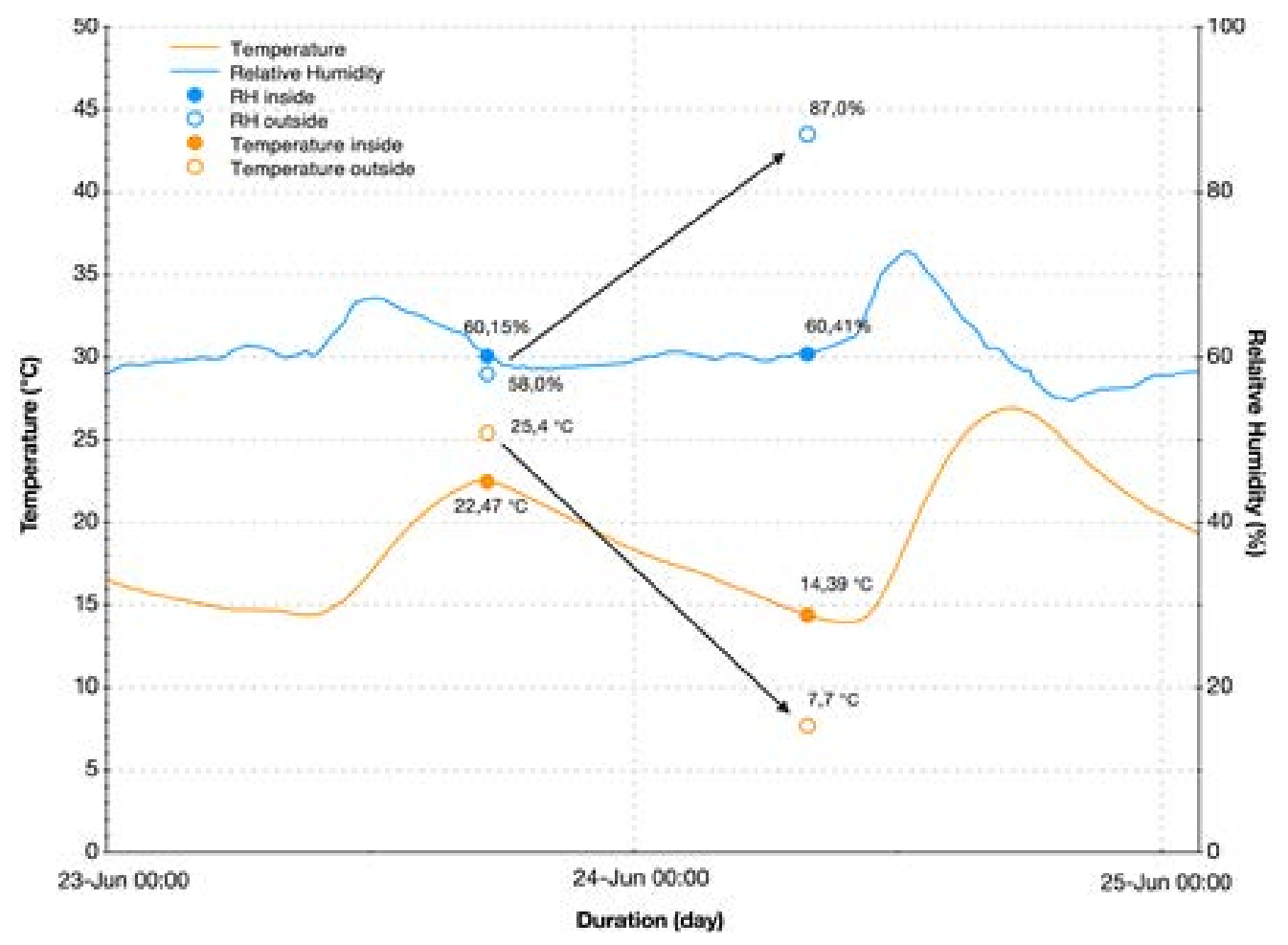

Figure 7: Insulation Effect of the Packaging at Port Elizabeth

Figure 7 also shows external values obtained from the weather station of Port Elizabeth for the one day when the ship was at the port. When the external values were $58 \% \mathrm{RH}$ and $25.4{ }^{\circ} \mathrm{C}$ at $4: 00 \mathrm{PM}$ the internal values were almost the same $(60.15 \% \mathrm{RH}$ $/ 22.47^{\circ} \mathrm{C}$ ), while the values were very different in the next morning at 7:00 AM.
The external and internal values were $60.41 \% \mathrm{RH}$ $/ 14.39^{\circ} \mathrm{C}$ and $87 \% \mathrm{RH} / 7.7^{\circ} \mathrm{C}$ in the morning. Because of the likelihood of being below dew point, the insulation effect from the use of packaging materials like triple wall corrugated and EPS could be noted. Summary temperature and $\mathrm{RH}$ values by stage of distribution are reported in Table 2 below.

\begin{tabular}{llccccc}
\hline & \multicolumn{3}{c}{ Temperature $\left({ }^{\circ} \mathrm{C}\right)$} & \multicolumn{3}{c}{ Relative Humidity (\%) } \\
& Min. & Avg. & Max. & Min. & Avg. & Max. \\
\hline Stage Europe continental & 11 & 17.2 & 24.7 & 29.9 & 58.1 & 76.5 \\
Stage Maritime & 10.7 & 19.6 & 27.2 & 61.3 & 65.4 & 67.7 \\
Stage South-Africa at port & 10.2 & 16.4 & 26.9 & 50.1 & 62.3 & 74.3 \\
Stage South-Africa continental & 9.2 & 15.0 & 19.4 & 43.0 & 64.3 & 79.1 \\
\hline
\end{tabular}

Table 2: Summary Temperature and RH Results 


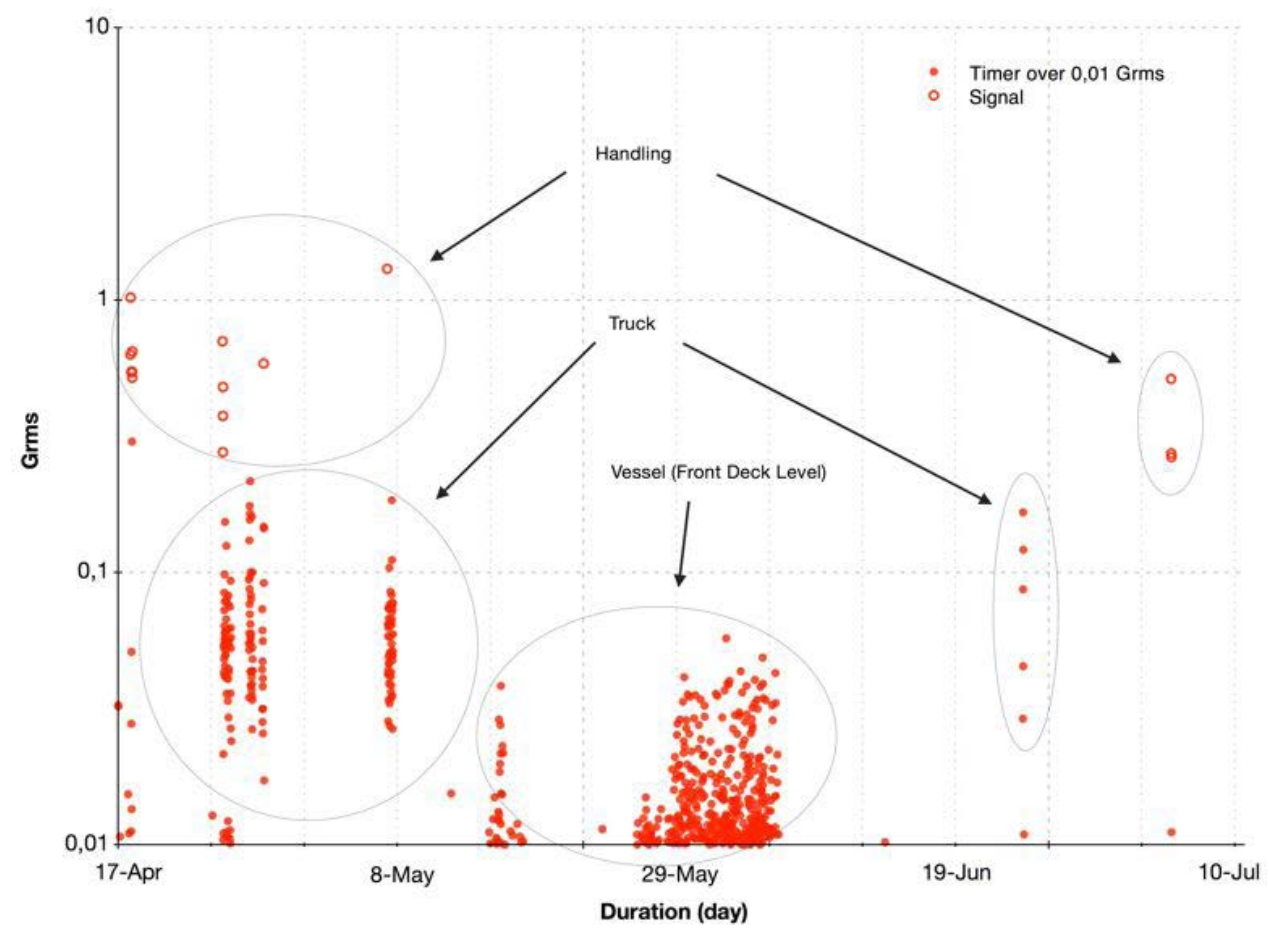

Figure 8: Vertical Vibration Events Recorded

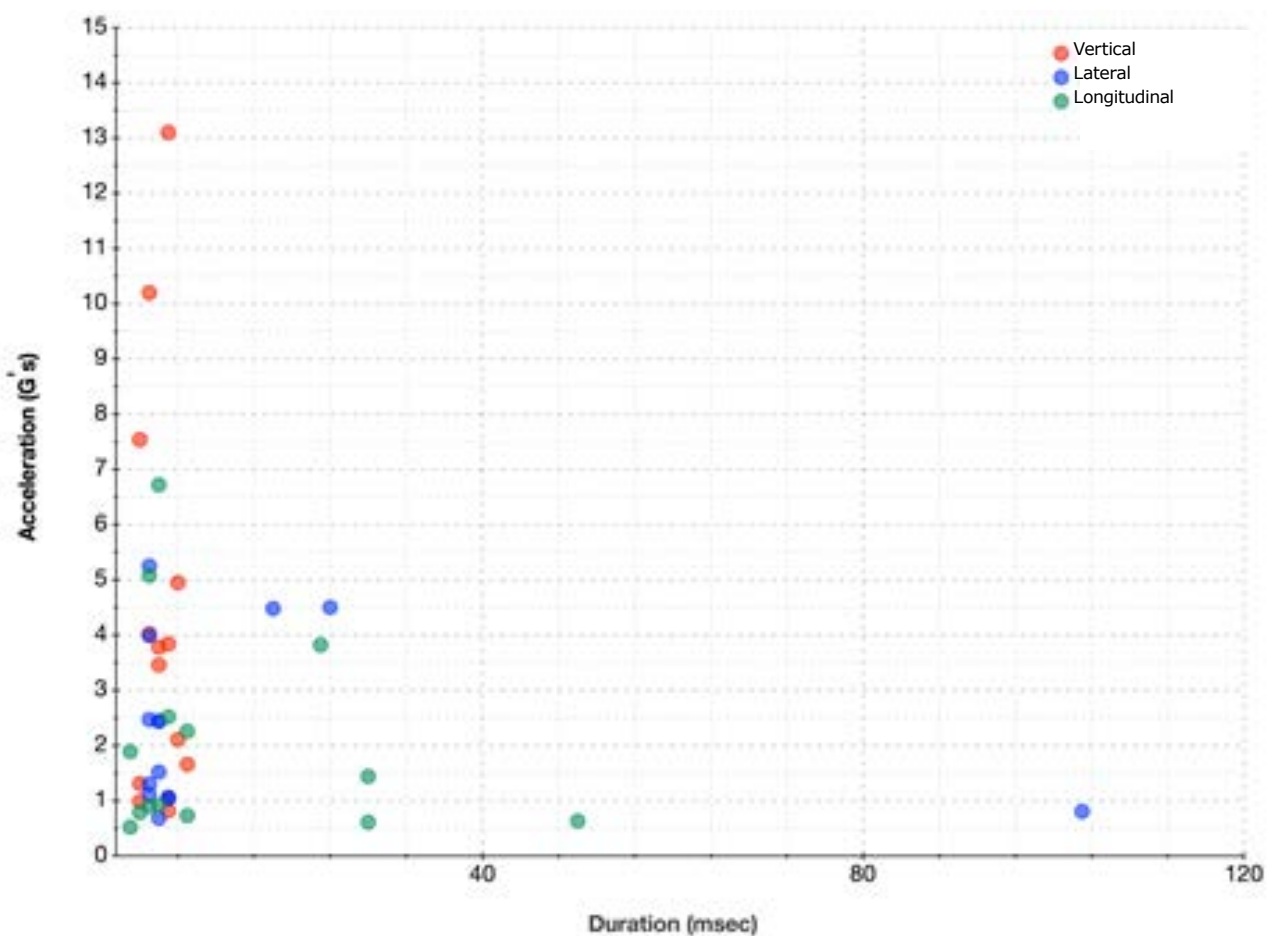

Figure 9: Recorded Events over 0.5G 
The second set of data discussed includes physical events represented by vibration inputs to the package system. Figure 8 presents the acceleration levels in Grms for vertical vibration events, and Figure 9 shows the vibration events in G's along over $0.5 \mathrm{G}$ against duration. The timer data is shown only by Grms over $0.01 \mathrm{~g}$ in order to make the locations of the significant events clearly visible. The varying intensity of the Grms values could be attributed to the different transportation modes and handlings associated with transfer between these modes.

Table 3 shows the magnitude and orientation of the ten most severe shocks during the shipment. The results show that the most severe physical events happened when the unit was handled at the ports or during transfer between storage and loading on trucks. The vibration and shock levels were generally very low when the package system was being transported by ship.
PDS were also developed for this shipment. Values recorded on the ship are separately shown in order to signify their low levels. The vertical vibration produced the highest overall Grms value of $0.209 \mathrm{~g}$ and represented truck shipments. Data is presented for all three orientations - lateral, longitudinal and vertical. Highest results from the vessel or ship were at $0.127 \mathrm{~g}$ clearly showing very low level of movement as compared to truck transport in both continents. Figure 10 shows the PDS for the top 5\% and $20 \%$ of the measured vertical, longitudinal and lateral vibration events, the remaining $80 \%$, and also all of the $100 \%$ events for trip segment 2 (Table 1) by truck. The frequency resolution is $1 \mathrm{~Hz}$.

\begin{tabular}{l|rrr}
\hline Event & Activity & $\begin{array}{c}\text { Acceleration } \\
\text { (G) }\end{array}$ & Orientation \\
\hline $\mathbf{1}$ & Handling at port & 13.11 & Flat - Bottom \\
$\mathbf{2}$ & Handling at storage & 10.16 & Flat - Top \\
$\mathbf{3}$ & Handling at storage & 7.54 & Edge - Bottom Right \\
$\mathbf{4}$ & Handling at storage & 7.54 & Flat - Left \\
$\mathbf{5}$ & Handling at commissioning & 6.72 & Flat - Left \\
$\mathbf{6}$ & Handling at commissioning & 5.25 & Edge - Front Left \\
$\mathbf{7}$ & Handling at storage & 5.08 & Edge - Left Back \\
$\mathbf{8}$ & Handling at port & 4.95 & Flat - Bottom \\
$\mathbf{9}$ & Handling at storage & 4.50 & Flat - Back \\
$\mathbf{1 0}$ & Handling at commissioning & 4.48 & Flat - Back \\
\hline
\end{tabular}

Table 3: Levels of the Ten Most Severe Shock Pulses 


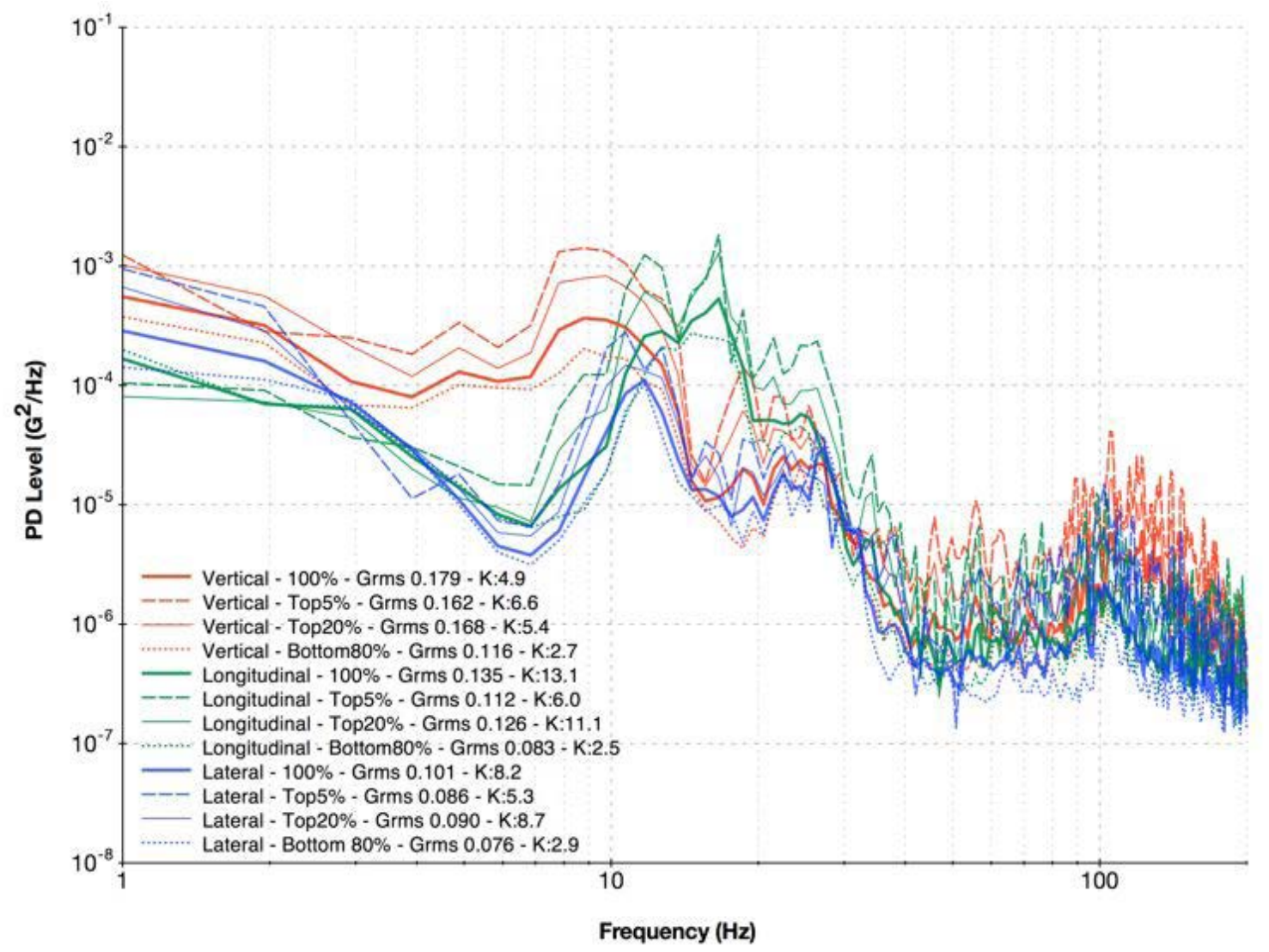

Figure 10: PDS for the Vibration Levels in Three Axes

Table 4: PSD Spectrum Break Points for Vertical Events between 1-200 Hz

\begin{tabular}{cc}
\hline Breakpoints $(\mathrm{Hz})$ & PD Levels $\left(\mathrm{G}^{2} / \mathrm{Hz}\right)$ \\
\hline 1 & 0.0004 \\
3 & 0.001 \\
8 & 0.001 \\
13 & 0.0002 \\
20 & 0.0002 \\
40 & 0.00001 \\
80 & 0.00001 \\
200 & 0.000002 \\
\hline
\end{tabular}

Table 4: PSD Spectrum Break Points for Vertical Events between 1-200 Hz 
PDS break points for the vertical events of the shipment between 1-200 Hz are shown in Table 4. As known from previous studies, the highest vibration levels in vertical orientation can be found between $1-20 \mathrm{~Hz}$, where the truck's suspension frequency and truck dynamics contribute to the vibration intensity as a function of road roughness and speed. The PD levels in lateral and longitudinal axes are much lower than in vertical axis, as reported in former studies [5]. The PD levels, after $20 \mathrm{~Hz}$, fall down rapidly. This trend is true for all three axes where above 20 $\mathrm{Hz}$, there is very little vibration intensity. Overall longitudinal vibration levels were generally higher than the lateral vibration.

\section{CONCLUSIONS}

Based on the results of this study, the following conclusions can be drawn:

The climatic environment and changes involving temperature and humidity changes during long-time transport involving moving between the northern and southern hemispheres can be critical on products, and therefore require appropriate packaging design criteria. Results from this study showed that the temperature and humidity levels can vary between 9 to $27^{\circ} \mathrm{C}$ and $\mathrm{RH}$ values can vary between 30 to $80 \%$ $\mathrm{RH}$. Therefore in intercontinental shipments across the equator climatic changes can cause changes in humidity, moisture content and dew point, causing condensation and other types of damage associated with corrosion and rust.

The transportation environment specific to truck vibration levels in Central Europe showed lower levels as compared to those measured in North America.

The vibration levels in all three orientations showed a significant reduction in transmitted acceleration to products above $20 \mathrm{~Hz}$.

The highest recorded shock events happened were measured when the package system was being handled as part of transfer between storage modes or moving to storage of the unit load itself.

The data and results from this study can be used to compare packaging vibration test methods used by packaging engineers. The data from this study can be used to develop test methods at lower levels that can reduce the protective packaging levels being currently used for these type of shipments, and also provide more sustainable solutions.

Based on the data provided from the climatic environment measurements from this study, accelerated climatic conditioning tests may be performed to test products and packages. 


\section{REFERENCES}

[1] Labaye E, Sjåtil PE, Bogdan W, Novak J, Mischke J, Fruk M, Ionuţiu O. A new dawn: Reigniting growth in Central and Eastern Europe. McKinsey Global Institute, 2013.

[2] International Monetary Fund (IMF). World Economic Outlook, Statistical appendix. International Monetary Fund: Washington D.C., 2012; 175-220.

[3] United Nations Conference on Trade and Development (UNCTAD), Trade and Development Report, 2013. United Nations: New York and Geneva, 2013.

[4] Brandenburg RK, Lee JJ. Fundamentals of Packaging Dynamics. L. A. B. Equipment, Inc.: Itasca, 2001.

[5] Singh, SP, Antle JR, Burgess GJ. Comparison between lateral, longitudinal, and vertical vibration levels in commercial truck shipments. Packaging Technology and Science 1992; 5: 71-75.

[6] Singh SP, Sandhu APS, Singh J, Joneson E. Measurement and analysis of truck and rail shipping environment in India. Packaging Technology and Science 2007; 20: 381-392. DOI:10.1002/pts.764.

[7] Rissi GO, Singh SP, Burgess G, Singh J. Measurement and analysis of truck transport environment in Brazil. Packaging Technology and Science 2008; 21: 231-246. DOI:10.1002/pts.797.
[8] Garcia-Romeu-Martinez MA, Singh SP, Cloquell-Ballester VA. Measurement and analysis of vibration levels for truck transport in Spain as a function of payload, suspension and speed. Packaging Technology and Science 2008; 21: 439-451. DOI:10.1002/pts.798.

[9] Chonhenchob V, Singh SP, Singh J, Sittipod S, Swasdee D, Pratheepthinthong S. Measurement and analysis of truck and rail vibration level in Thailand. Packaging Technology and Science 2010; 23: 91-100. DOI:10.1002/pts.881.

[10] Singh SP, Marcondes JA. Vibration levels in commercial truck shipments as a function of suspension and payload. Journal of testing and evaluation 1992; 20 : 466-469.

[11] Singh J, Singh SP, Joneson E. Measurement and analysis of US truck vibration for leaf spring and air ride suspensions, and development of tests to simulate these conditions. Packaging Technology and Science 2006; 19: 309 - 323. DOI:10.1002/ pts.732.

[12] Singh SP, Joneson E, Singh J, Grewal G. Dynamic analysis of less-than-truckload shipments and test method to simulate this environment Packaging Technology and Science 2008; 21: 453-466. DOI: 10.1002/ pts.787.

[13] Chonhenchob V, Singh SP, Singh J, Stallings J, Grewal G. Measurement and analysis of vehicle vibration for delivering packages in small-sized and mediumsized trucks and automobiles. Packaging Technology and Science 2012; 25: 31-38. DOI:10.1002/pts.955. 
[14] Kurniawan MP, Chonhenchob V, Singh SP. Measurement and analysis of vibration levels in 2 and 3 wheel delivery vehicles in South East Asia. In Proceedings of 19th IAPRI World Conference on Packaging 2014, Melbourne, Australia.

[15] Singh SP, Saha K, Singh J, Sandhu APS. Measurement and analysis of vibration and temperature levels in global intermodal container shipments on truck, rail and ship. Packaging Technology and Science 2012; 25: 149-160. DOI: 10.1002/pts.968.

[16] Singh SP, Burgess GJ, Marcondes JA, Antle JR. Measuring the package shipping environment in refrigerated ocean vessels. Packaging Technology and Science 1993; 6: $175-181$.

[17] Jarimopas B, Singh SP, Saengnil W. Measurement and analysis of truck transport vibration levels and damage to packaged tangerines during transit. Packaging Technology and Science 2005; 18: 179-188. DOI:10.1002/pts.687.

[18] Topper E, Singh SP, Singh J. Packaging requirements for less-than-truckload shipments to reduce damage-paint, televisions, and copiers. Journal of Applied Packaging Research 2010; 3: 63-82.

[19] Singh, S. P., Antle, J., Singh, J., Topper, E and Grewal, G. "Load Securement and Packaging Methods to Reduce Risk of Damage and Personal Injury for Cargo Freight in Truck, Container and Intermodal Shipments.” Journal of Applied Packaging Research. Vol. 6: No. 1, Article 6, 2014
[20] Topper, E., Singh, S. P. and Singh, J. "Packaging Requirements for Less-ThanTruckload Shipments to Reduce Damage - Machinery and Machine Parts, Doors and Windows and Miscellaneous Items". Journal of Applied Packaging Research, Vol. 5, No. 2, pp. 93-106, April 2011

[21] Topper, E., Singh, S. P. and Singh, J. "Packaging Requirements for Less-ThanTruckload Shipments to Reduce Damage Furniture, Appliances and Boxed Freight". Journal of Applied Packaging Research, Vol. 5, No. 1, pp. 43-56, January 2011

[22] Wallin B. Developing a random vibration profile standard. PreShipment Testing Newsletter, International Safe Transit Association 2007; 1, 20-24.

[23] Kottek, M., J. Grieser, C. Beck, B. Rudolf, and F. Rubel, World Map of the KöppenGeiger climate classification updated. Meteorol. Z. 2006, 15, 259-263. DOI: 10.1127/0941-2948/2006/0130. 